\title{
The Study of Chinese-English Public Signs Translation
}

\author{
Xuechuan $\mathrm{He}$ \\ Shanxi Normal University, Linfen, China
}

\begin{abstract}
Public signs are special texts that are common in public places. And functions of them are to provide information or to remind readers of some requirements. As China strengthens exchanges with other countries in economy and culture, the translation of public signs was born at the right moment. The public sign translation is an important link in building a harmonious society, establishing an international metropolis and promoting economic development. Firstly, this paper introduces the definition of public signs and summarizes their main features and functions. Secondly, the existing literature and the results of research in China are summarized. By analyzing the problems existing in the Chinese and English public sign translation, this paper puts forward some suitable translation strategies.
\end{abstract}

Index Terms - public sign translation, translation strategies

\section{INTRODUCTION}

Modern life is inseparable from public signs, which not only provide convenience to people, but also convey the progress of civilization and society. With the globalization and internationalization of the world, the communication between countries is becoming more and more close. Under different cultural and linguistic backgrounds, as an important public symbol, English public signs serve as a medium and bridge for cultural communication among different nationalities. To a large extent, public signs remove language barriers to communication among different nationalities and promote national development and opening-up. The importance of public signs is self-evident.

Public signs, which mean the written language for the public to see in public, are the most common practical language in people's life. They are a special style of writing that is open to and facing the public in order to achieve certain communicative purposes. Public signs are widely used in our life, almost everywhere, such as road signs, billboards, shop signs, publicity in public places, tourism profiles and so on. With the rapid development of economy and the deepening of the reform and opening-up policy, China's economic cooperation with other countries is increasing. International communication is becoming more and more frequent. Chinese culture is gradually favored by friends from all over the world. In order to facilitate the basic life of foreigners, many first-tier cities, such as Beijing, Shanghai and Guangzhou, have begun to use bilingual public signs widely, especially in public places, such as subway, airport, station, gas station, ticketing center, museum, gymnasium, historic sites and customs, etc. Public signs gradually exist in all aspects of people's lives. They will be highlighted with the opening of cities' image and the improvement of civilization. However, the translation of public signs in China is not satisfactory from the current situation, there are a lot of grammatical or spelling errors and violations of translation habits, so that foreigners often stand up and laugh at a public sign, which affects China's international image seriously. The main reason is that most of the previous studies focused on the micro-level data collection and annotation error correction stage, without a practical theoretical system to guide the translation of public signs from the macro-level. This paper explores the English translation of public signs from a new perspective.

The author hopes that the research in this paper can arouse people's attention to the translation of public signs, improve the quality of public signs translation to make China more open and modern. At the same time, the paper regards the methods and strategies aiming at effectively guiding the Chinese-English translation of public signs.

\section{LITERATURE REVIEW}

The translation of public signs is a new field in translation studies. For a long time, the research on its system is not enough. The study of translation of public signs in China began in the late 1980s. The purpose of previous studies is to arouse foreigners' attention to the international image of China. Since then, a number of academic papers and articles have been published to explore the problems in the translation of public signs, which has greatly promoted the standardization of public signs translation in China. There are two scholars publish an article and put forward five principles of "simple, clear, proper tone, moderate and moderate humor" which should be followed in the translation of Chinese into English (Ni Chuanbin, Liu Zhi, 1998). After entering the twenty-first Century, the translation of public signs has gradually become the focus of attention in the translation field. From the earliest collection of examples to the analysis of translation errors of public signs from the perspective of semantics, linguistic features, functional features, cultural connotations and cultural differences, and then to explore the translation of public signs. Generally speaking, 
public signs translation is mainly studied from the perspectives of eco-translatology, communicative translation theory, Cross-Cultural Theory and relevance theory. Since 1990, the study of Chinese English translation of public signs has gradually become a hot topic of domestic scholars. Scholars have done a lot of research on it. According to Relevance Theory, two scholars hold that on the basis of the theory of public sign translation, translators should pay attention to the role of context to improve relevance and expand cognitive environment in order to achieve pragmatic equivalence. (Liu Jiangang, Yan Jianhua, 2005). Another author puts forward the communicative translation strategies of public signs was based on the analysis of the present situation of Chinese English public signs translation (He Xueyun, 2006). From the perspective of cultural differences between Chinese and English public signs, people explores the influence of cultural differences on communication and probes into the translation of Chinese and English signs from the perspective of pragmatics (Zhao Xiang, 2006).

The Chinese-English translation of public signs must be on the same occasion in Chinese-English culture and have the same function of public signs so as to replace them directly. However, some of the current domestic Chinese public language in the English-speaking countries cannot find any traces. In this case, the translator should first consider some of the public signs with Chinese characteristics. The purpose is to introduce Chinese culture, publicity in China, and achieve the filling and conversion of Pinyin through legal interpretation. (Bei Zhu, Shan Aimin, 2002). Therefore, the mismatch, misunderstanding and abuse of public signs can lead to adverse consequences. For the translation of public signs, we must apply skopos theory. First of all, people must translate the cultural habits of readers so that the proper translation of public signs can be obtained and the language environment can be purified to improve our international image.

\section{The INTRODUCTION OF PUBLIC SignS}

\section{A. Definitions and Characteristics}

Public signs refer to the general instructions for reminding and warning in public places. It refers to written language in public places. In China, the translation of public signs began in 1989. Scholars have made continuous exploration and Research on the translation of public signs, and have achieved encouraging results. With the development of China's economy and the accelerated pace of opening up, friendly exchanges and economic cooperation between China and other international communities are increasing. The public language of cities is gradually adopted in both Chinese and English. The Public signs are an important part of external publicity and are widely used in every aspect of our lives. With the successful convening of APEC, G20 and BRICS summits, the translation of public signs plays an increasingly important role. Therefore, the translation of public signs is of great significance for maintaining the image of China's cities. People must pay enough attention to public signs. However, the translation of public signs in China started late and lacked systematicness and standardization. Errors and problems are still very obvious.

Some scholars describe the public signs as follows: "It is the text language that people see in public places". There is the corresponding argument in English, "public signs". Some scholars define the public signs as: "The public signs are a kind of special style text common in public places, the graphical text of them is concise and easy". Some scholars outline definition of public signs are more comprehensive, "The signs is text and graphic information open to the public, and is used to announce, explain, prompt, display, warn, mark people's production, life, ecology, industry etc.” (Dai Zongxian \& Lv Hefa, 2006).

English public signs are characterized by conciseness, standardization and formality. Its characteristics can be expressed by the English words beginning with the letter C, which can be expressed as five English words: Concise, Conventional, Consistent, Conspicuous and Convenient.(Han yongqing, 2009) Public signs are written in public places to attract attention of people. This unique style can be seen everywhere in people's life. For example, “出口 Exit”, “售 票处 Ticket Office”, “餐饮区 Dining area”...However, the characteristics of public signs are summarized as four points in the paper. The first characteristic is conciseness, which is the easiest to understand.(Le Meiyun, 1989) Conciseness is the most important linguistic feature of public signs. It requires that the words and phrases in public signs are simple and concise, and the language strives to express the best effect in the simplest form. Most busy people want to get the most accurate information in a limited time in public places where people come and go. Only simple public signs will never be forgotten. Therefore, imperative sentences are mostly used in public signs. In terms of vocabulary, public signs seldom use complex words, but verbs and sorting. The use of phrases will make language more concise and clear. For example, “会议中心 Conference Center”, “阶梯教室 Lecture Hall”, “小心夹脚 Watch Your Feet”, “严禁超载 No Overloading”, “减速慢行 Slow Down”, “请注意台阶 Please Watch The Steps”, “请勿触摸 Hands Off”, “切勿近火 Keep Away From Fire”, “不准吐痰 No Spitting”, “保持通畅 Keep Clear”...

The second characteristic is straightforwardly. Public signs convey information directly to the public, not indirectly and euphemistically, and avoid using gorgeous rhetoric or esoteric terminology, which is totally different from literary works. Such as “售完 Sold Out”, “登记住宿 Check In”, “现在营业 Open Now” etc. Abbreviations are widely recognized and widely used in public facilities and public services. With the development of international communication, public signs are becoming more and more standardized and internationalized. Some public signs have been used internationally. The translator does not have to translate in a big way, but only needs to directly refer to the original text of the target language country. 
The third characteristic is standardization. As ambiguity plays a vital role in public life, and any ambiguity or misunderstanding may lead to adverse consequences. Because of the differences in history, cultural background and language habits between countries, over time, many common public signs have already been translated by convention, and they are expressed in a unified standard. Therefore, English public language should follow fixed usages or practices. Such as: “残疾人专用”, it can’t be translated as “For people with disabilities” because of inappropriate choice of words. It should be translated as "Accessible Pathway".

The fourth characteristic is to strictly prohibit the use of unused words or unfamiliar words. Since most of the readers of public signs are civilians, the translation of public signs must take full account of the cultural level and reading habits of readers, and try to avoid using unusual words, colloquial expressions, slang and professional terms. For example: the translation of “扶梯暂停使用” can be translated “This escalator is temporarily shut down”. It is used more accurately and truthfully. Therefore, in order to take care of foreigners from different countries and regions, the translation of public signs should use the most common, simple and easy-to-understand words, so as to avoid misunderstanding.

\section{B. Function of Public Signs}

Public signs have four functions of guidance, encouragement, restriction and constraint in practical application. Public signs provide information and services to the public. The purpose of these signs is to provide instructions or convenience for the public, such as “服务信息 Service Information”, “租车服务 Car Rental”, “6 折 $40 \%$ off” etc... These public signs provide thoughtful information services, without any additional restrictions or coercion.

Indicative public signs and indicative public signs are similar in characteristics and have no specific meaning. They only provide information to make people know how to do or how to observe public order. Tip signs are widely used in various forms, but there is no compulsion. People can decide whether to accept the proposal according to their actual situation. For example: “贵重物品、现金请交服务台保管, 否则后果自负 Valuable articles and cash should be handed to General Service Desk for Safekeeping”. Remind customers to take care of their belongings. If it is lost, the hotel is not responsible. The hotel has notified customers of the possible consequences through public signs, prompting them to decide whether to take action or not. The characteristics of public signs will surely attract attention of people. For example, “预留席位 Reserved”, “油漆未干 Wet Paint”, “售完 Sold Out”, “容易爆炸 Explosion”, “限高 Maximum Height”, “加收 10\%服务费 10\% Service Charge”, “单行道 One-Way Street” and “危险 Danger” etc. According to the tips of public signs, people often take appropriate actions in public.

Next is the restrictive function. In the light of the relevant public's words and deeds, restrictive public signs do not make people feel rude, rude, but also put forward the direct limit and requirements. Compared with the first two types of public signs, this kind of public signs has certain limitations, people should abide by these regulations, and otherwise it will damage the public interest, even in violation of the law or regulations. The common limited signs are: “减速慢行 Slow Out”, “右侧行驶 Keep Right”, “凭票入内 Ticket Only”, “保持安静 Keep Silence”, “只准公交车通过 Buses Only”, “对号入座 Seat By Number”, “12 岁以下儿童免费 Free For Children Under 12”, “限高 3.3 米 Restricted Height 3.3M".

The forth is the compulsory function. The compulsory effect of compulsory public signs is more obvious, which requires the public to take or not take such actions. The use of straightforward, tough and unexplained words is the linguistic feature of mandatory public signs, which are usually used in imperative sentences to begin with "no" or “prohibition”. For example: “严禁停车 No Parking”, concise pointed out here cannot stop, otherwise it may cause serious consequences; “严禁随地吐痰 No Spitting” is used to express the imperative mandatory orders to prohibit people spitting.

\section{The Problems Existed in the Translation of Public SignS}

For the translation of public signs, the original and the target text have same purposes, so methods and strategies of the translation used by translators in the whole translation process should satisfy the common purpose. Moreover, the translator must have a good understanding of the cultural and communicative environment of the target language country in order to satisfy the coherence of the translation. Due to various constraints, most translators lack the understanding of English and American languages, life experience, or direct contact with English and American public signs, which leads to inaccurate translation of public signs. In an advantageous article, the translation of public signs is difficult. On the basis of understanding the source text, the translator clarifies the similarities and differences between English and Chinese public signs on the basis of understanding the source text.

Firstly, there are some illustrations to violate the purpose of the act in translation. “保护水资源，建设新家乡” The protection of water resources, the construction of a new home" is a public service advertising. It was translated as "Protect water resource, Construct new hometown". And the correct translation of Dao Xiao Mian is the Sliced Noodles. In these illustrations, the wrong translations have no grammatical errors. But in the first example, "protect" and "construct" are verbs as the subject, it is an imperative. This is a compulsory expression, which makes people feel uncomfortable when they see it, which is contrary to the original pragmatic purpose. But if it is changed to "Protecting" and "Constructing", the present participle will be much better. There is a rallying point. In the second example, perhaps in order to integrate into the global society, Chinese Pinyin appears simultaneously in English translation of many 
places. Simple Pinyin does not accord with the coherence of language and communication. This combination of Pinyin and English spelling may cause a lot of reading barriers for foreigners who come to China for the first time.

Secondly, in translation, there is an illustration to violate the intratextual coherence. Such as a warning message in front of a scenic spot: “当心跌倒” is translated into “Don’t Fall Down”. Because of the snow, the ground of the scenic area is slippery. The manager of the scenic area deliberately reminds the tourists to be "careful". If only from a grammatical point of view, the translation does not seem to be picky. In this case, the original translation focuses too much on the intertextual coherence, without take into account the intratextual coherence. Although there is no error in grammar, the form is faithful to the original text, but the translation does not conform to the cultural tradition of the British and American public signs from the intertextual coherence rule. The correct expression of safety in public is usually "Caution Wet Floor", "Caution Slippery Surface”, "Caution Trip Hazard” etc.

Thirdly, there are some illustrations to violate the intertextual coherence in translation. In a shopping mall, there is a hint next to the stairs of "care step". It is also mistranslated into English that "Take care the step". The purpose of this public language sign is to remind customers that they need to pay attention to foot safety when walking there in this shopping mall. But the meaning of the translation has become a concern about the steps. The correct translation should be "Mind the step" or "Be care of the step". From this example we can see that the confusion of two phrase, "take care of" and "be careful of", leads to inconsistencies in meaning between English and Chinese, and it violates the coherence of intertextuality, faithfulness, legality and the loss of original information after revision.

There is a similar example that "careful to meet" is translated as "Take care your head", but its correct translation should be “be careful your head” or “Mind your head”. Everywhere people can see the signs about “小心碰头”, “当心 玻璃” and other public words, someone translated them in accordance with the literal meaning as "Take care of your head", "Be aware of glass door". This kind of translation can make the text more appropriate and correspond one by one between Chinese and English. "Be careful" does not violate the principle of intertextual coherence. And the latter is more consistent with intertextual coherence and the expression of target language readers. Thus, the verbatim translation of the condemnation is undesirable.

\section{The Strategies of the Chinese-English Translation of Public Signs}

The important part of public sign translation is to convey information so that readers can feel, think and act. The translation of public signs is a complicated process, which is influenced by cultural customs, occasions and so on. People should pay enough attention to the translation of public signs. The translator should be reader-centered, strive to improve language skills and grasp the differences between English and Chinese translation. Translators should avoid reducing errors in the process of translation between Chinese and foreign languages and cultural exchanges. Therefore, familiarity with language features and striving for conciseness should be the focus of public translation. The translation of public signs follows the following principles:

First of all, translators should follow the principles of translation and use international public signs to express them. Public signs are widely used to provide convenience for people's lives. We must use advanced translation to provide the same convenience for foreign friends. How can translators save time and energy to complete high-quality translation? In fact, the simplest and most practical way is to use English public signs directly. Because English public signs must take care of the feelings of English-speaking people, and they can understand the meaning. There are many similarities between Chinese and English public signs. We can choose English expressions directly. This is "borrowing translation". This can not only avoid mistakes, but also provide effective guidance and help to foreigners. Just like "private parking", "lost property" and so on, it can be referred directly. However, in translation, we should also choose a more mature and standardized country as a reference, and choose the most accurate one after comparing.

Such as “不要践踏草坪”, people use “Keep off the grass” in most places, but it is translated as "Please give me a chance to grow" in some European lawn. This translation is more consistent. Therefore, the best translation of public signs should follow the principle of use. Another illustration is the traffic sign, which is “不要疲劳驾驶” that means "Do not drive when tired". This is syntactically nothing wrong. But British translated it as "Tiredness kills, take a break", and the Americans translated it as "Stay alert, stay alive". By contrast, public signs in British and American countries are more authentic. Therefore, in the face of these translations, translators can borrow the original English directly.

The second point is that the translator should grasp the cultural differences and pay attention to the habits of the target readers. Every language has its own historical and cultural accumulation. There are many obvious differences in people's way of thinking, living habits and language use in different cultural backgrounds, and they will be reflected in public signs. In the translation of public signs, cultural habits of readers should be put in the first place. Language is the carrier of culture and that can not exist without culture. In the process of public sign translation, it is very important for the translators to respect the cultural habits of readers and put them first in the process of translation.(He Xueyun, 2006) Chinese translators should understand the linguistic features and functional meanings of public signs, determine the linguistic style of the target language, and choose the appropriate vocabulary for translation. The most important thing is to communicate with the international community, so that foreign friends can read it easily, so that they do not feel ambiguous about public signs. 
There is an illustration “红旗手”, which is translated by some people as "Red flagger", in order to allow foreigners to understand Chinese culture. But there will be no foreigners know the "red flag" which Chinese people called. It actually contains "Advanced, model" and other implied meaning, such as "Model worker" or "Advanced worker", which used to express the meaning of "Red flagger".

Third, the translator should try to translate the text concisely. The translation of public signs should be easy to understand, clear, direct and standardized. Every translator should pay more attention to eliminating the difficulties of readers in reading and communicating. In the translation of public signs, translators choose to use a large number of nouns, verbs, gerunds, phrases and acronyms. Whether it is the nature of service, explanation or restriction or compulsory public signs, most of the use of the above words is rationally adjusted to meet the requirements of public signs. Translators should not use vague words in the process of translation. Considering language habits and cultural level of readers, common vocabulary should be used in public signs.

For example, “利刀伤人” means that “Blade is sharp, take care of your hand". It is a public sign in razor. In fact, the public sign remind people look out the blade, that write of translation seem a bit crowded and cumbersome. It should be translated as: Sharp shade! Another illustration is “贵宾候车室”. It means that “Distinguished guests wait for a bus at the place". This is a public sign for a bus station waiting room. The translation of the original text is a complete sentence, but it does not conform to the linguistic features of public signs. In addition, the original translation makes foreign tourists feel uncomfortable, as if the station divides the tourists into grades. To eliminate this misunderstanding, people use the strategy of "concise", translated it as "Reserved Waiting-room". "Reserved" is the euphemistic expression of "distinguished". The original "guests", "wait for a bus" and "at the place" are all redundant text.

\section{CONCLUSION}

The application of public signs has global characteristics. And every language and culture are inseparable. Different languages represent different cultures. The translation of Chinese-English public signs includes the differences of languages, choice of words, style and intonation, and the collision of traditional culture. Therefore, in order to complete the translation of the two languages, the translator must fully understand the text and cultural connotations.

Many public signs are available both inside and outside China. Therefore, they should try to be read in English in the same way, and they should have the same functions as English public signs. However, there are still some public signs with Chinese characteristics in China, or there is no substitute for them in English-speaking countries. It is worth noting that when translating these public signs, the purpose is not only to provide necessary information for foreign tourists but also to let foreign friends understand Chinese culture. And then, the translation should be consistent with discourse coherence. Although there is no direct substitute for English, translators should try to conform to the conventions of English public language. And finally, we should meet the intertextual coherence. The English translation should be the same as the meaning of the Chinese public signs, cannot arbitrarily tamper with. English translation should have the same meaning as Chinese public signs and should not be tampered with at will. Skopostheorie has a wide range of practicability. It emphasizes the characteristics of text types and helps to improve translators' 'linguistic awareness of communicative functions and functional translation units and improve translation efficiency.

Public signs are an indispensable part of national development. Their quality directly reflects the comprehensive quality of a country and affects the image of China in the world. For a long time, translation errors of public signs have appeared. This paper studies the Chinese-English translation of public signs. From the perspective of semantics and aesthetics, the author believes that the translation of public signs is a good translation strategy. At the same time, the author believes that, while advocating the democratic participation of the government, it will change the current situation of Chinese-English translation of public propaganda in China.

\section{ACKNOWLEDGMENTS}

Time goes by, and two years' life in the graduate school is coming to the end. During the time, it is my tutor's care, love and instruction that accompany with me. What comes along is the encouragement and support from my friends and classmates. I will leave the campus and step into society, and I want to say "thank you" to those who have guided me, help me and encouraged me.

Above all, my thanks go to my supervisor Mrs. Li. She has helped me a lot from the beginning of topic-selecting to the translating practice as well as to the writing and revising of my paper. With her guidance and advice, I have greatly improved in my professional knowledge. Therefore, I'd like to express my sincere respect and gratitude to my teacher.

Secondly, I want to say "thanks" to my classmates and friends who have constantly encourage me, inspired me and supported me during process of writing the paper. It is those people who gave me courage to finish my paper. I've really enjoyed to making progress together with them.

Finally, I regard my parents as the ones deserve my special thanks. They are my most stoic fans. It is their support that made me through the painful but fruitful writing process. They give me the most unselfish love. I can't think of other way to repay them other than working harder and being a better daughter and better person. 


\section{REFERENCES}

[1] Bei Zhu, Shan Aimin. (2002). On the Linguistic Features of English Public Signs and Chinese Translation. Journal Beijing Second Foreign Language Institute, 05, 76-79.

[2] Dai Zongxian, Lv Hefa. (2006). Globalization and Standardization of Bilingual Graphic Symbols. Advertising Panorama(China Signage),06,38-45.

[3] Han Yongqing. (2009). Investigation and Research on the Standardization of Chinese and English Translation of Public Signs in Nanyang. Journal of Hotan Teachers College, 3, 170-171.

[4] He Xueyun. (2006). The Present Situation of Chinese and English Translation of Public Signs and Communicative Translation Strategies. Foreign Languages and Their Teaching, 03, 57-59.

[5] Le Meiyun. (1989). Linguistics and Theory of Translation. Journal of Foreign Languages, 5, 36-41.

[6] Liu Jangang, Yan Janhua. (2005). On Pragmatic Equivalence Translation of Notices. Shanghai Journal of Translators For Science and Technology, 4, 32-35.

[7] Ni Chuanbin, Liu Zhi. (1998). The Principles and Examples of English Translation of Markers. Shanghai Journal of Translators For Science and Technology, 2, 19-21.

[8] Zhao Xiang. (2006). Cultural Differences and Pragmatic Translation of Chinese and English Signs. Foreign Language Education, 2, 72-74.

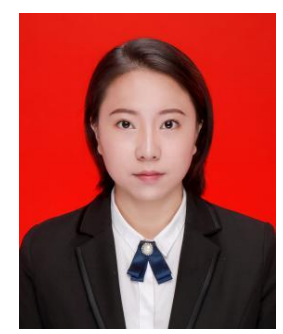

Xuechuan He was born in Datong, Shanxi Province of China in February 1993. She received her bachelor degree in 2016

She is a graduate student in the School of foreign languages, Shanxi Normal University, Shanxi, China in 2019. Her research interest is mainly translation. 